\title{
Vic's Story
}

\section{Vic McKinney}

\section{REFLECTIONS ON FATHERHOOD}

As a boy growing up in Cape Town, South Africa, I always imagined that I would be a father one day. It was something that I took for granted. I had a very comfortable childhood growing up in a middle-class suburb in South Africa. I did not focus on fatherhood too much, I just imagined that I would go to university after completing school and then travel as much as I could until settling down in my early 30 s with a family. That was my vague idea. I just always assumed that I would be a dad.

I was also very fortunate in that my father and I were very close-I was an only child and as a young boy he was my idol. By my late teens we were like best friends. This was a privilege not lost on me, especially when I saw how some of my close friends battled in their relationships with their fathers. Furthermore, it was heartening to know how proud he was of me, especially when I was accepted to, and enrolled at, the University of Cape Town as a fine art student.

V. McKinney $(\varangle)$

Cape Town, South Africa

e-mail: victor.mckinney@alumni.uct.ac.za; sky@iafrica.com

(C) The Author(s) 2021

$\mathrm{X}$. Hunt et al. (eds.), Physical Disability and Sexuality, https://doi.org/10.1007/978-3-030-55567-2_9 
So when we had an accident on the road a month after my 19th birthday and towards the end of my first year at university, my life was turned upside down. My father died in the accident, and I was rendered paralysed from the shoulders down.

The early years following the accident were hard to get through. This was Primarily because, when I came out of rehabilitation (after an extended period of about nine months in hospital), I discovered that I had two disabilities - the one was my paralysis, and the other was how I was now regarded by other people.

During my confinement in hospital I was given an application form to live in a special residential home for people in wheelchairs. The message appeared quite clear to me: if you could not be healed, if you could not be fixed, then you did not belong in mainstream society. This was very difficult for me to handle. In an instant I had gone from being an active student who enjoyed the outdoors, photography and playing sport on a weekly basis, to being a social outcast that most people did not know how to talk to.

I did not go into the residential home. My mom and I felt that I would never get the level of care that I needed and would not survive very long in such a place. So I came home.

It was extremely challenging, to say the least. I was 20 years old and my mom had to look after me like I was a baby. I relied on her for everything: to get washed and dressed, and even to eat and drink. I became a boy again. A terrified little boy who needed his mommy. This had a profound effect on me. To exacerbate things, my mother had to give up her new job and her life to look after me. I felt like a burden, and this feeling had a substantial impact on me.

For many years after the accident, I thought that I could not be in a relationship - that I would be a burden, and that I would not be able to contribute to any relationship as an equal partner. This sense of myself as being inferior halted my maturity in many ways. At the time of my accident I was establishing my place in the world as a young man in terms of my masculinity and sexuality-but all that went out the window when I acquired a disability. It was extremely difficult, especially in the early years of my paralysis, to deal with the attitudes of people without disability in public.

When people looked at me, I felt as if they only focused on my wheelchair and did not see me as a person. Often, people would look away straightaway, pretending as if they did not see me. Sometimes people 
would just stare at me without saying anything. I have never been able to just blend into the crowd, since being a wheelchair user there is always some kind of reaction to my disability. As a young university student, when I met people, the first questions they would ask me were, 'What do you do?', and 'Do you have a girlfriend?' We are all social beings. These two questions link you to your fundamental value in society: the ability to work and to have children one day.

However, when people met me when I was in a wheelchair, the first question on their mind was 'What happened to you?' I found that to be the most common reaction people without disability had to me, and, while it was an okay question in and of itself, the problem was that people's interest in me did not go any further than that. That is what was-and sometimes still is - really difficult. It makes me sad. Generally, people do not expect me to be able to do anything or to be in a relationship because I'm in a wheelchair.

In the early days of my disability, I was not seen as a sexual being anymore-or so I thought. Six years after my accident, I did get into a relationship that was quite intense and physical. It was short-lived, but had a profound effect on me. It awoke feelings within me that I had suppressed and gave me the belief that I could be attractive to someone. The new sense of confidence it bestowed on me saw me enter into a few subsequent relationships over the next 10 years.

My next relationship was with a friend I had known before my accident, and we had a summer romance. We had a good connection and I felt relaxed around her, which helped me not to stress about things. For example, I did not know how well my body would perform sexually, but I decided not to worry about it. After all, I had been through so much, what else could go wrong? It was great just to be close to somebody and I discovered that intimacy goes far beyond intercourse alone. From a physical point of view, over the years, the sensation in my body had gradually increased and I also discovered I could wiggle my toes and fingers slightly. During this relationship I was discovering what my body could and could not do in bed and it was quite exciting. I found out, to my pleasant surprise, that I could get an erection naturally while kissing. I did not ejaculate during sex, but afterwards my urine would be cloudy and so I realised that I was producing sperm. I gained a great deal from this relationship and it gave me a lot of confidence to be with the opposite sex again. 
I grew a lot more confident and comfortable with my sexuality and I was out to have fun. A while after that, I got into a long-term relationship. It was a very physical relationship and that was quite important to me at the time. However, looking back at it, it was not a very mature relationship and after we had moved in together it did not last very long. The topic of children came up and I quickly realised that we were in no way ready for that. I refused to have children at that stage and the relationship ended soon after.

On a positive note, however, it did get me out of the house that I had shared with my mom for so many years. I was now living in my own place and did a lot of necessary growing up. Another positive factor was that during this relationship I discovered that I could ejaculate naturally. When it happened it was a very pleasant surprise and was the first time that I'd done so in 17 years. I realised I could probably have done it earlier but I just hadn't focused on it. It can take quite a while but then again, that is also the fun part!

However, with that comes a word of warning for somebody else in my position. A few times after I had ejaculated I immediately got a pounding headache, so I spoke to my doctor about it. He said that this is in fact extremely dangerous as it is hyperreflexia-this is an over-reactive response from the nervous system which can occur in people with spinal cord injuries. So he gave me a tablet to take $10 \mathrm{~min}$ beforehand which would regulate and decrease my blood pressure and so minimise the chances of having a stroke. It is also interesting to reflect upon the fact that during my rehabilitation from my accident, which occurred in 1987, no health professional ever discussed with me the possibility of being in a future sexual relationship, let alone having children. It simply was not thought of and no one took into account how it might affect my view of myself or my well-being overall. In the eyes of the medical fraternity, and society in general, once I became paralysed I was not considered as having a sexual identity anymore. My feeling is that this is still very much a problem for people with disabilities today, particularly in South Africa. Current Western culture may have a more open attitude about being sexually active, however, I think it is still very difficult for most people with disabilities to be seen as having a sexual identity, let alone being regarded as equal members within their communities.

Sometime after the break-up, a close friend of mine came over one day and he recalls how I had decided not to have any long-term relationships anymore-I had decided that they were too complicated and too 
painful. So he was surprised when he called me about a month later and I told him that I had met the love of my life, Emma. We had met at the University of Cape Town, where I was studying, and it was that special occurrence when we both just knew that we were meant to be together. We started dating and were discussing our future together very soon after that. We talked about having children within two weeks of beginning our relationship. We were married a year later in 2009, 22 years after I became paralysed, and started trying to have children about six months later.

One of the first things we did was have my semen tested and analysed. We discovered that the chances of falling pregnant naturally were very slim. My sperm count was on the low side, only about 20 million-the required amount is usually between 25 million and 500 million. Furthermore, besides the count, a semen analysis looks at the motility (the ability to swim forward) as well as the morphology (shape) of the sperm. The shape of my sperm was fine but they were a bit sluggish in movement.

To fall pregnant, we initially tried artificial insemination (AI) a number of times. It is much cheaper than the in vitro fertilisation (IVF) process and also slightly less invasive for the woman concerned. Basically, on the selected day of ovulation, I produced a sperm sample in the morning which was taken to the clinic to be 'washed' and processed and a small extract taken to be inserted in Emma. Emma took medication to facilitate conception. Also, I would produce a sample at home-it is far more comfortable and research has shown that producing samples at home as opposed to the clinic is more successful. After the sperm was inserted via a specialised syringe by the doctor, it was basically a waiting game to see if we had fallen pregnant. We did not expect much at the beginning but were still hopeful, and consequently disappointed when it did not work for three months in a row. After the third disappointment we were due to go overseas for a conference and decided to do IVF once we had returned the following month. I discovered from our doctor that falling pregnant is basically a numbers game. We had a minimal chance of falling pregnant naturally; the artificial insemination increased the odds somewhat but not a great deal, whereas the IVF process presented a $35 \%$ chance of success. It is, however, quite expensive and an uncomfortable process, for the woman in particular-my dear wife had to inject herself with medication daily to increase her egg production which made her feel bloated and uncomfortable. Again, on a set day of the ovulation process, I produced a sample in the morning which was taken to the clinic to be prepared-the important thing is to keep it warm, and my wife recalls keeping the sample cup with 
my fresh sperm in her bra while driving $10 \mathrm{~min}$ down the road to the clinic! The whole process was very clinical, and yet so deeply personal. What a story to share with our children when they're old enough to understand!

At the clinic they extracted eggs from Emma and injected my sperm directly into a few of the promising looking ones in the hope that they would fertilise. This part of IVF is known as Intracytoplasmic sperm injection (ICSI) and only requires one sperm per egg, which greatly reduces the chances of having twins. The fertilisation takes about five days after which we had one really good embryo (fertilised egg) and Emma and I went back to the clinic to have this transferred into her womb. Thereafter the waiting began for us, along with attending many checkups (especially during the first three months) to see whether the embryo had taken and the pregnancy was going smoothly.

We were very fortunate that it took first time and we had a beautiful healthy boy. Having my first son was an incredible experience. He spent a lot of his first six months asleep on my chest. We soon bonded and have the same connection that I had with my father-and in a way it is like having my dad back, which is amazing (Image 9.1). Having grown up as an only child, that was my mindset - and when Emma said that she wanted another child it kind of threw me. I was not averse to the idea, I had just not thought about it and felt that I had everything I wanted in our first boy. However, I was happy to try for another child and we went through the IVF process again three and a half years later. Fortunately, it was successful the first time once again and today we have two sons. It was wonderful to go through the same, yet different, experience with a second child. It is amazing how different the boys are in personality. I am fortunate that as an academic researcher I work a lot from home and so have time to spend with my boys and watch them grow up. These are valuable years and you cannot get them back once they have passed. During her pregnancy, Emma recalls that while being out in public with me (and having a very pregnant tummy) she received lots of quizzical and confused stares from onlookers, wondering whether I could possibly be the father. Sadly, these kinds of attitudes are quite common. But you never quite get used to them. One time, in a shopping centre, a woman came up to my wife and asked how we had sex.

This presents a challenge to my wife and I-both of us are academics with PhD's. We lecture on disability awareness and consider ourselves educators regarding disability issues. In that sense, we appreciate that 
Image 9.1 Two of Vic's favourite images include Emma when she was pregnant and getting a kiss from his young son Jamie. These photographs are on his mirror in his room (Photo by Vic McKinney)

society in general is ignorant about disability and we need to change these views. However, there's a time, place and way to address personal topics properly and a shopping centre is not one of them. Emma admits that she was conflicted regarding her response to this rude woman-tempted to say that she has a great time and swings from the chandeliers, and equally tempted to tell the woman to get lost! In the end she chose to ignore her and we carried on shopping. These days I sometimes get the same quizzical looks when I'm driving around in my wheelchair with my two sons on board-one sitting on my lap tray and one sitting on my footrest between my feet.

For me, having my family has changed my identity-I am a father and a husband, first and foremost. My disability is secondary. However, I know that that is not how other people necessarily see me, and that is where change needs to happen in society.

Looking back, I sometimes regretted how much time I wasted after my accident, going through those relationships and getting my act together 
before I started studying and working properly. However, I realise now that it was necessary-I simply needed that amount of time to grieve and readjust to my new life of non-movement in a wheelchair. Furthermore, those relationships I had were stepping stones in my maturation, and it makes me appreciate even more what I have today.

I am also acutely aware of the privilege I have as a White wheelchair user in South Africa, and I jumped at the chance of being part of research into disability and sexuality, of which this book is a product. Most of the work and research Emma and I are involved in is dedicated to improving the lives of people with disabilities. People are genuinely surprised when I explain that we estimate there are over 30,000 wheelchair users in the greater Cape Town area, because we hardly see them. They have a fundamental human right to participate in society - to be educated and find employment and be in a relationship. And to have children, as most of us take for granted.

And to have children, as most of us take for granted.

We, as a society, have a long way to go to change negative attitudes towards disability. As humans, our sexuality is a fundamental part of who we are, and when you acquire a disability, sadly, it is often taken away from you. My wish is for people to realise that anybody can acquire a disability at any time. It may change you physically, and perhaps intellectually, but it does not change who you are, your value in society or your sexuality and sexual needs, including the desire to experience love and start a family.

Open Access This chapter is licensed under the terms of the Creative Commons Attribution 4.0 International License (http://creativecommons.org/licenses/ by $/ 4.0 /)$, which permits use, sharing, adaptation, distribution and reproduction in any medium or format, as long as you give appropriate credit to the original author(s) and the source, provide a link to the Creative Commons license and indicate if changes were made.

The images or other third party material in this chapter are included in the chapter's Creative Commons license, unless indicated otherwise in a credit line to the material. If material is not included in the chapter's Creative Commons license and your intended use is not permitted by statutory regulation or exceeds the permitted use, you will need to obtain permission directly from the copyright holder.

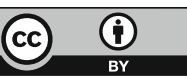

